\title{
Coats' syndrome: long term follow up
}

\author{
Devron H Char
}

\begin{abstract}
Aim-To increase the understanding of the long term results in pseudoretinoblastoma eyes with infantile Coats' syndrome.

Methods-This study design was a retrospective case review. 10 patients were analysed who were initially referred with a diagnosis of retinoblastoma but had Coats' syndrome on the basis of ocular oncological evaluation. Vision, fundus photography, ultrasonography, and computed tomography scans were obtained and evaluated. Changes in vision and retinal status were measured.

Results-The initial age at presentation was 2.4 years (range $0.25-4$ years). All patients had retinal detachment at diagnosis. Nine of 10 retinas were reattached after various treatments. Reattached retinas had closure of peripheral telangiectasia and visible intraretinal crystals. Vision was dismal. At last follow up (mean 8.8 years), only two patients had $20 / 400$ or better visual acuities. Five eyes had no light perception despite early treatment to reattach the retina. Nine of 10 eyes remain cosmetically acceptable. One patient wore a cosmetic shell.

Conclusions-Long term results indicate that these eyes can be salvaged and the retina reattached but the visual outcome is poor.

(Br f Ophthalmol 2000;84:37-39)
\end{abstract}

Coats' syndrome has been a subject of controversy since the first description of this retinal vascular abnormality in $1908 .{ }^{1}$ Retrospectively, the clinical entity was probably first reported by Brailey in $1876 .^{2}$ In his seminal publication, Coats described three types of lesions, although he recognised that the third group, now known as von Hippel-Lindau angiomas, was probably different from the others. ${ }^{1}$ In his third publication in 1912, Coats combined his first two groups, mainly young males with unilateral intraretinal exudates with and without visible retinal vascular abnormalities and haemorrhage. ${ }^{3}$ The retinal vascular abnormalities included telangiectasia, microaneurysms, capillary dropout, and both large vessel wall aneurysms and arteriovenous communications.

Confusion arose on several fronts. One, almost from the onset, there were overlapping descriptive terms; it took almost 40 years for Reese to definitively inculcate in the ophthalmic literature that Leber's miliary aneurysms were an initial manifestation and part of Coats' syndrome, although Leber probably knew it. ${ }^{4}$
Two, the aetiology of this syndrome remains obscure. It usually presents unilaterally in young males without evidence of systemic disease. Many investigators studied infectious, inflammatory, metabolic, and other aetiologies, and some suggested different names for this condition. ${ }^{6}$ Three, several other local and systemic disease processes can produce retinal exudation, and many publications as late as the 1960s included very different disease processes under a slightly different rubric, Coats' disease. ${ }^{7}$ In addition, Coats' disease has been described as a syndrome in association with several hereditable ocular diseases including retinitis pigmentosa, Hallermann-Streiff syndrome, Senior-Loken syndrome, Cornelia De Lange syndrome, Parry-Romberg syndrome and the epidermal naevus syndrome..$^{8-13}$

In the 1956 Gifford Lecture, Reese described two children who presented with retinal telangiectasia and developed complete manifestation of Coats' syndrome with extensive intraretinal exudation, haemorrhage, and exudative detachment. ${ }^{5}$ Several light and electron microscopic studies have demonstrated that the basic defect appears to be loss of the normal vascular endothelial barrier with all of the other changes (intraretinal exudates, lipid deposits, lipid laden macrophages, cholesterol clefts, and haemorrhages) secondary to that abnormality. ${ }^{6}{ }^{14-16}$

Coats' syndrome has a mean age of diagnosis, in most series, of approximately 9 years. ${ }^{16-20}$ In older children and young adults the diagnosis is usually straightforward. Very young children often present with a partial or total retinal detachment; the possibility of retinoblastoma has resulted in many of these eyes being enucleated. ${ }^{11}{ }^{17} 21$ Newer diagnostic modalities have allowed elimination of unnecessary enucleations in patients with Coats' syndrome. ${ }^{22}$

Unfortunately, infants with Coats' syndrome have more advanced disease, often with a total retinal detachment; the long term functional and anatomical survival of such eyes is uncertain. ${ }^{17}{ }^{19}$ Most reports of Coats' syndrome cases have been in older children or young adults; in a compilation of five series, only 33 of $181(18 \%)$ patients presented at 4 years of age or younger. Usually, only in very young children with Coats' syndrome with leucocoria and more than two quadrants of retinal detachment is Coats' syndrome likely to be confused with retinoblastoma. Efforts have been made to avoid removal of eyes in children with Coats' syndrome. We present the long term follow up of such eyes referred with the diagnosis of a retinoblastoma to determine the visual status and globe retention in those patients.
Accepted for publication 16 August 1999 


\section{Materials and methods}

A retrospective analysis of ocular oncology files was performed. Files of patients who were initially referred with diagnosis of retinoblastoma and later assigned a diagnosis of Coats' syndrome were reviewed. Patients who had at least 4 years of follow up after their initial evaluation were included in this study. All initially had exudative retinal detachments.

All patients were examined both awake and under anaesthesia after being referred with a possible retinoblastoma. In addition to clinical evaluation, computed tomography (CT) imaging and, in many cases, ultrasound imaging were also performed.

Patients were treated with several different types of management. Two patients had no therapy. Five patients were treated with both subretinal drainage and cryotherapy. The subretinal fluid in these cases was analysed in cytopathology. One patient was treated with multiple laser sessions, and two with cryotherapy alone. Follow up was obtained for all patients from both their current ophthalmologist or ourselves.

\section{Results}

Ten patients met the criteria for inclusion in this study; they had a mean age of 2.4 years old (range $0.25-4$ years) at diagnosis. Nine were male and one was female. Eight were white, one was African-American, and one was oriental. Seven patients presented with a total retinal detachment. Three patients presented with smaller degrees of retinal detachment. One had a quadrant of detachment and a subretinal mass; two others had a hemidetachment with an apparent subretinal mass. All patients had between one and three quadrants of peripheral telangiectatic vessels visible.

On examination under anaesthesia, all had findings typical of Coats' disease with yellowish-white subretinal exudates and peripheral telangiectatic vascular abnormalities. Ultrasound revealed retinal detachment, without calcium. On computed tomograph (CT) scans (Fig 1) there was no calcium visible and retinal detachment was observed. In patients who had subretinal drainage, the cytopathological findings of that fluid were consistent with Coats' syndrome and demonstrated lipid laden macrophages.

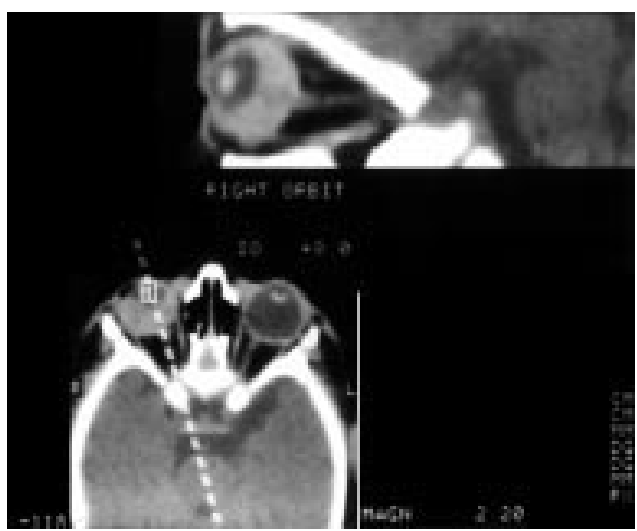

Figure 1 Axial CT scan demonstrates retinal detachment and subretinal exudation without calcification.

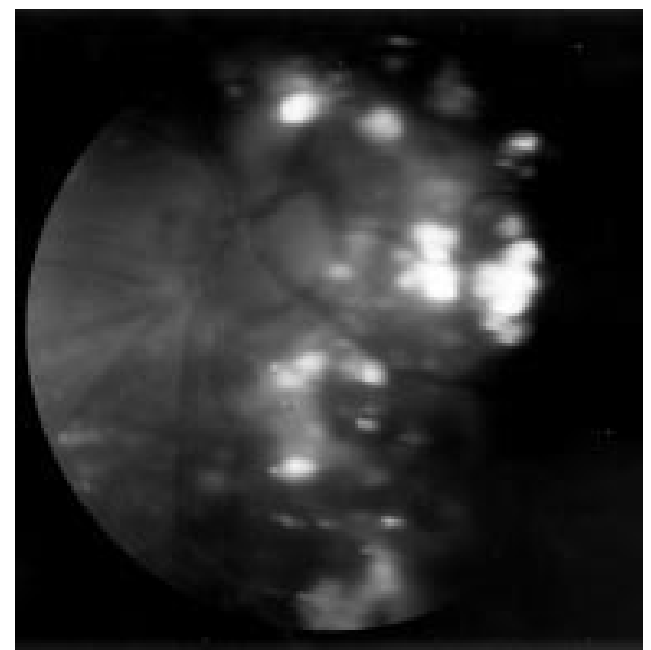

Figure 2 Intraretinal crystalline deposits visible in the attached retina 10 years after treatment.

Before therapy, most children had vision recorded as probable light perception; none had good central maintained acuity in the involved eye. As discussed under methods, two patients were observed, five were treated with both cryotherapy and drainage, one patient received only laser, and two had only cryotherapy. In all operated cases, the laser or cryotherapy was used to treat and close retinal telangiectasia. Three of the patients required repeated treatments, one for failure to close vessels, and the other two for new areas of telangiectasia.

The mean follow up after initial evaluation was 8.8 years with a range of $4-16.3$ years. At last examination, the final visual acuity ranged between $20 / 200$ and no light perception (NLP). Five patients had NLP, one patient had LP, two patients had counting fingers vision, and one each had visual acuities of 20/200 and $20 / 400$. On last examination, nine of the 10 patients have flat retinas with some crystalline deposits visible (Fig 2); one patient, who had both cryotherapy and drainage, has a low lying chronic retinal detachment.

In addition to initial therapies, one patient with a blind eye underwent both a cataract and strabismus surgery elsewhere. Two other patients have had late strabismus surgery. One patient now has developed an early band keratopathy. One patient has an unsightly eye for which the referral physician performed a Gunderson flap and placed a shell prosthesis.

\section{Discussion}

Historically, most infantile Coats' syndrome eyes were enucleated because of the possibility of retinoblastoma; in a series from Reese's clinic, Gomez Morales noted that 13 of 18 enucleations were because of the possibility of malignancy. ${ }^{17}$ Similarly, in other series a number of eyes were enucleated with the incorrect diagnosis of retinoblastoma. ${ }^{15}{ }^{16}$ Improved awareness of the clinical pattern of Coats' syndrome and the use of ancillary imaging tests including CT has allowed correct diagnosis of this entity. ${ }^{22}$ Clinically, the presence of yellowish subretinal exudation and peripheral telangiectasia are 
virtually pathognomonic for this diagnosis. In children under 3 years old with leucocoria, the absence of intraocular calcification on thin section CT almost rules out the diagnosis of retinoblastoma; using newer spiral CT technologies often these examinations can be done awake. ${ }^{23}{ }^{24}$ In very rare cases, a fine needle aspiration biopsy may be indicated, and in those settings a child with Coats' disease will show lipid laden macrophages unlike a retinoblastoma in which malignant cells are observed. ${ }^{25}$ Using the above diagnostic techniques and criteria, fortunately no Coats' eye has been removed under a mistaken diagnosis of retinoblastoma in this practice.

The aetiology of Coats' disease remains uncertain. ${ }^{167141522}$ A number of different vascular findings have been described involving both the arterial and venous system; the initiating event as well as the earliest changes are not certain. Reese re-emphasised the concept that both Leber and Coats probably recognisednamely, that multiple peripheral retinal aneurysms were an early sign of the disease. Reese also reported two patients who presented with retinal telangiectasia and later developed full blown exudative detachments. ${ }^{5}$ Several other investigators have further amplified the disease description. The mean age at diagnosis was approximately 10 years, and the temporal retina was more commonly involved than the nasal area. ${ }^{119} 2026$

The natural history of an individual patient with Coats' syndrome is difficult to predict and depends partially upon age. As an example, in a study by Campbell, only two children under age 3 were included and both of those had enucleations. ${ }^{21}$ Even in the large series reported from New York by Gomez Morales, most of the very young children were enucleated. ${ }^{17}$ In that later series, in cases with 5 years' follow up, the course was variable with some eyes developing total retinal detachments and neovascular glaucoma while others did not. Harris noted that one quarter of the patients under age 5 developed neovascular glaucoma on follow up. ${ }^{26}$ Ridley and colleagues also noted that the disease in young children was more severe; 10 of those patients had three or more quadrants of telangiectasia; three of 10 developed total detachment and glaucoma. She and her co-authors emphasised that new areas of disease can develop and may require additional therapy. ${ }^{20}$

The optimal management of severe Coats' syndrome with exudative detachment is uncertain. Several workers have suggested that cryotherapy may be more effective in more severe disease. ${ }^{1626}{ }^{27}$ Usually laser is only effective if the retina is attached. It was interesting that two of the 10 patients in this study did not receive treatment, and the retinas in both those eyes eventually reattached without worse visual outcomes than the treated eyes. Similarly, in those two cases there were no more complications than in the eyes that were treated aggressively. This series differed from others by having a younger population and longer follow up. It is possible that the prompt treatment did diminish the incidence of neovascular glau- coma. No eyes were enucleated because they became painful. Alternatively, it is conceivable that some of these eyes did develop neovascular glaucoma and then spontaneously regressed. Other investigators have noted since the 1920s that spontaneous regression can occur in association with this disease process. ${ }^{28}$

We observed that almost all eyes can be maintained in situ. Long term follow up (mean 8.8 years) demonstrated that nine of 10 retinas remained reattached. All but one patient had a cosmetically acceptable eye. The visual prognosis was dismal; only two patients had $>20 / 400$ vision despite the retinas having been reattached, often within a few months of diagnosis.

Patients with Coats' disease can be correctly diagnosed with non-invasive tests, and with treatment the retina can be reattached. Most of these eyes may be retained and usually have adequate cosmesis although strabismus developed and was treated in three of the 10 patients. Visual outcome was dismal.

1 Coats G. Forms of retinal disease with massive exudation. Roy London Ophth Hosp Rep 1908;17:440-525.

2 Brailey WA. Curator's pathological report. Roy London Ophthal Hosp Rep 1876;8:548-9.

3 Coats G. Über Retinitis Exudativa (retinitis hemorrhagica externa). Graefes Arch Ophthalmol 1912;81:275-327.

4 Leber TH. Retinitis exudativa (Coats), retinitis und chorioretinitis serofibrinosa degenerans. Graefe-Saemisch Augenheilk 1915;7:1267-319.

5 Reese AB. Telangiectasis of the retina and Coats' disease. Am f Ophthalmol 1956;42:1-8.

6 Woods AC, Duke JR. Coats's disease. $\mathrm{Br} f$ Ophthalmol 1963;47:385-412

7 Manschot WA, de Bruijn WC. Coats's disease: definition and pathogenesis. Br F Ophthalmol 1967;51:145-57.

8 Morgan WE III, Crawford JB. Retinitis pigmentosa and Morgan WE III, Crawford JB. Retinitis pigmento
Coats' disease. Arch Ophthalmol 1960;79:146-9.

9 Burch JV, LeVeille AS, Morse PH. Ichthyosis hystrix Burch JV, LeVeille AS, Morse PH. Ichthyosis hystrix
(epidermal nevus syndrome) and Coats' disease. Am $\mathfrak{f}$ Ophthalmol 1980;89:25-30.

10 Folk JC, Genovese FN, Biglan AW. Coats' disease in a patient with Cornelia de Lange syndrome. Am f Ophthalmol 1981;91:607-10.

11 Schuman JS, Lieberman KV, Friedman AH, et al. SeniorLoken syndrome (familial renal-retinal dystrophy) and Coats' disease. Am f Ophthalmol 1985;100:822-7.

12 Newell SW, Hall BD, Anderson CW, et al. HallermannStreiff syndrome with Coats disease. $\mathcal{F}$ Pediatr Ophthalmol Strabismus 1994;31:123-5.

13 Gass JD, Harbin TS Jr, Del Piero EJ. Exudative stellate neuroretinopathy and Coats' syndrome in patients with progressive hemifacial atrophy. Eur f Ophthalmol 1991;1:2prog.

14 Wise GN, Horava A. Coats' disease. Am f Ophthalmol 1963; 56:17-23.

15 Tripathi R, Ashton N. Electron microscopical study of Coats' disease. Br F Ophthalmol 1971;55:289-301.

16 Tarkkanen A, Laatikainen L. Coats' disease: clinical, angiographic, histopathological findings and clinical management. Br F Ophthalmol 1983;67:766-76.

7 Gomez Morales A. Coats' disease: natural history and results of treatment. Am f Ophthalmol 1965;60:855-65.

18 Egerer I, Tasman W, Tomer TT. Coats' disease. Arch Ophthalmol 1974;92:109-12.

19 Chisholm A, Foulds WS, Christison D. Investigation and therapy of Coats' disease. Trans Ophthalmol Soc UK 1974;94:335-41.

20 Ridley ME, Shields JA, Brown GC, et al. Coats' disease: evaluation of management. Ophthalmology 1982;89:1381-7.

21 Campbell FP. Coats' disease and congenital vascular retinopathy. Trans Am Ophthalmol Soc 1977;74:365-424.

22 Char DH. Clinical ocular oncology. 2nd ed. Philadelphia: Lippincott, 1997

23 Arrigg P, Hedges RT 3d, Char DH. Computed tomography in the diagnosis of retinoblastoma. $\mathrm{Br} f$ Ophthalmol 1983;67:588-91.

24 O'Brien JM, Char DH, Tucker N, et al. Efficacy of unanesthetized spiral computed tomography scanning in initial evaluation of childhood leukocoria. Ophthalmology 1995; 102:1345-50

25 Char DH, Miller TR. Fine needle biopsy in retinoblastoma. Am f Ophthalmol 1984;97:686-90.

26 Harris GS. Coats' disease, diagnosis and treatment. Canad $\mathcal{F}$ Ophthalmol 1970;4:311-20.

27 McGrand JC. Photocoagulation in Coats' disease. Trans Ophthalmol Soc UK 1970;90:47-56.

28 Friedenwald H, Friedenwald JS. Terminal stage in a case of retinitis with massive exudation. Trans Am Ophthalmol Soc $1929 ; 27: 188-94$. 